\title{
Biotypic Diversity and Resistance to the Raspberry Aphid Amphorophora agathonica in Pacific Northwestern North America
}

\author{
Michael Dossett ${ }^{1}$ and Chaim Kempler \\ Agriculture and Agri-Food Canada, Pacific Agri-Food Research Centre, P.O. Box 1000, Agassiz, BC, \\ Canada VOM $1 A 0$
}

\begin{abstract}
AdDITIONAL INDEX words. aphid resistance, Rubus idaeus, Rubus strigosus
Abstract. Resistance to colonization by the raspberry aphid (Amphorophora agathonica Hottes) has been an important objective in North American red raspberry (Rubus idaeus L.) breeding programs since the 1930s because of its effectiveness in controlling the spread of aphid-transmitted viruses in red raspberry. The most widely used source of resistance in North America has been the gene $A g_{1}$ from 'Lloyd George'. The widespread use of $\boldsymbol{A g}_{1}$ to control aphids led to the appearance of a resistance-breaking biotype in British Columbia, Canada, in 1990. Our objective was to identify biotypes of $A$. agathonica present in the commercial red raspberry production region of southwestern British Columbia and northwestern Washington and determine what sources of resistance may still be effective against this pest. We collected 12 aphid isolates and screened them against 15 raspberry cultivars and four selections. Although it has been widely believed that only two biotypes (regular and $\mathrm{Ag}_{1}$-breaking) of $\mathrm{A}$. agathonica were present in the region, we identified six distinct biotypes and characterized them by their ability or inability to colonize a differential set of raspberry cultivars. This has confirmed the loss of previously recognized and unrecognized sources of resistance in some cultivars. The data also support the presence of a seventh biotype that has not yet been observed. In addition, we confirmed resistance from three sources of wild North American red raspberries that hold up to each of these biotypes. Our results will serve as a guide for future efforts to characterize the prevalence of different aphid biotypes in the region and the identification of new sources of resistance for breeding.
\end{abstract}

Interest in breeding raspberries with resistance to the raspberry aphid Amphorophora agathonica dates back to the 1920 s, when it was first identified as the primary vector for the raspberry mosaic virus complex in North America (Rankin, 1927; Rankin and Hockey, 1922). Winter (1929) was the first to describe resistance to $A$. agathonica in red raspberry, conducting a series of experiments showing that aphids in Minnesota were unable to colonize plants of 'Herbert' in isolation. Huber and Schwartze (1938) followed with work in Washington classifying 'Herbert' as "partly resistant" because of mixed results from greenhouse tests and field observations, but also found that 'Pyne's Imperial', 'Pyne's Royal', and 'Lloyd George' were each highly resistant and that progenies of 'Lloyd George' segregated for aphid resistance (Huber and Schwartze, 1938).

Despite this early work, little effort was focused on identifying and characterizing resistance to A. agathonica until the 1950s and 1960s when Stace-Smith began conducting a series of experiments on the various components of the mosaic virus complex. Stace-Smith (1960) found that in addition to being resistant to colonization, aphids had a low rate of virus acquisition from 'Lloyd George'. At the same time, Daubeny began work identifying sources of resistance to the aphid in

Received for publication 31 July 2012. Accepted for publication 5 Sept. 2012. This project was supported by funding through the Developing Innovative AgriProducts Initiative with support from Agriculture and Agri-Food Canada, the Raspberry Industry Development Council of British Columbia, the Washington Red Raspberry Commission, and the Lower Mainland Horticulture Improvement Association.

We thank Silverio Nanni for help in screening the seedling populations for aphid resistance and Danielle Lightle for helpful discussion on the topic and review of this article.

${ }^{1}$ Corresponding author. E-mail: Michael.Dossett@agr.gc.ca. southwestern British Columbia (Daubeny, 1972; Daubeny and Stace-Smith, 1963) and demonstrating that resistance from 'Lloyd George' was conferred by a single dominant gene, which he designated $A g_{1}$ (Daubeny, 1966). In addition to 'Lloyd George', Daubeny (1972) confirmed resistance in 'Pyne's Royal' and identified resistance derived from two other European sources, 'Burnetholm' and 'LaFrance'.

Although breeding work has remained focused on the use of $A g_{1}$, Daubeny and Stary (1982) recognized the potential for an aphid biotype capable of overcoming this source and surveyed wild red raspberry germplasm from across North America for new resistance. They identified resistance in wild Rubus strigosus Michx. collected from three locations on the outskirts of Ottawa, Ontario, Canada, and determined that inheritance was likely the result of complementary dominant alleles, which they postulated to be present in each of these locations and designated $\mathrm{Ag}_{2}$ and $\mathrm{Ag}_{3}$ (Daubeny and Stary, 1982). The $\mathrm{Ag}_{2} / \mathrm{Ag}_{3}$ model proposed by Daubeny and Stary (1982) was based on an inability to decipher segregation ratios for either a one- or a two-gene model in the greenhouse. As a result, they monitored colonization of the seedlings in the field over the next two growing seasons and found that the field data fit a two-gene model. The original sources of $\mathrm{Ag}_{2}$ and $\mathrm{Ag}_{3}$ have been used in breeding raspberries since they were first selected 30 years ago. However, a lack of genetic markers and phenotypic differences to separate them from $A g_{1}$ has limited the ability to select for them and determine their presence or absence in the selections and cultivars that have been developed from them in the time since.

Historically, only one biotype of $A$. agathonica was recognized in North America (Converse et al., 1971). This biotype was controlled by $\mathrm{Ag}_{1}$ until the early 1990s, when aphids were 
found colonizing $\mathrm{Ag}_{1}$ plants in the field (Daubeny and Anderson, 1991, 1993). There are currently four aphid-transmitted viruses known to infect raspberries in northwestern Washington and southwestern British Columbia: raspberry leaf mottle virus, raspberry latent virus, rubus yellow net virus, and black raspberry necrosis virus (Halgren et al., 2007; Quito-Avila et al., 2012; Tzanetakis et al., 2007). These viruses contribute to a decline in cane health and fruit quality, resulting in a shortened life of the infected plantings. As a result, selecting for durable resistance to $A$. agathonica remains a major breeding objective (Kempler et al., 2012), and the Agriculture and Agri-Food Canada, Pacific Agri-Food Research Center (AAFC-PARC) breeding program in British Columbia has continued to select seedlings for aphid resistance on a yearly basis working under the model of two aphid biotypes, regular and $\mathrm{Ag}_{1}$-breaking. In recent years, the reaction of seedling families to routine aphid screening has not fit expected segregation ratios for resistance under this model. This has made it difficult to determine which parents are conferring resistance in crosses and whether so-called resistant seedlings are truly resistant or represent escapes.

Until reliable sources of strong horizontal resistance can be identified, future success in developing cultivars with durable aphid resistance will rely on the ability to pyramid or combine resistance genes, which have not already been compromised, to minimize the risk of aphids overcoming single-gene resistance. The objectives of this project were to survey raspberry aphids in southwestern British Columbia to identify the different biotypes present and characterize which cultivars they will colonize, thereby developing a differential set of cultivars that can be used for screening aphids from the field and determining which biotype they belong to. This will not only provide a framework for future studies monitoring the prevalence and relative importance of different aphid biotypes, but will also help breeders to better identify what sources of aphid resistance have been overcome and what sources of resistance are available for germplasm improvement.

\section{Materials and Methods}

Plant materials. All plants for this experiment were produced either from tissue-cultured plantlets of cultivars maintained in the screenhouse collection of virus-indexed raspberry germplasm at AAFC-PARC or from root cuttings taken from dormant roots of screenhouse plants. Plants were potted in 2.8-L pots and grown in the greenhouse until they produced actively growing shoots elongated to a minimum of $8 \mathrm{~cm}$ before being introduced to aphid colonies. Plants were watered regularly and given a balanced liquid fertilizer (Classic; Plant Products Co., Brampton, Ontario, Canada) weekly throughout this period to promote fast growth and tender tissue attractive to aphids.

ApHID Colonies. A total of 12 aphid isolates were collected from the field and greenhouses at the AAFC-PARC research center in Agassiz, British Columbia, Canada, from the field at the AAFC-PARC substation in Abbotsford, British Columbia, Canada, and from commercial raspberry fields within an $\approx 10-\mathrm{km}$ radius of Abbotsford, British Columbia, Canada. Adult aphids from the field were established in screened cages (BugDorm-2120 Insect Tent; MegaView Science Co., Taichung, Taiwan) on potted plants of either 'Meeker' or the cultivar on which they were found in the field. All aphids were maintained in the greenhouse under supplemental lighting with a 16-h daylength and temperatures fluctuating between $23{ }^{\circ} \mathrm{C}$ (day) and $18{ }^{\circ} \mathrm{C}$ (night) for the duration of the project. Colonies used for final screening were derived from a single female so that biotypes could be determined from clonal isolates without mixed colonies confounding results.

To establish a clonal virus-free stock colony for colonization assays, a single adult aphid was taken from each initial colony and placed on a detached leaflet of 'Meeker' held in a petri dish with a moist section of paper towel. Newly emerged nymphs were then collected from the petri dish in the mornings and evenings for $3 \mathrm{~d}$ and transferred to screened cages holding plants, which had previously indexed negative for aphid-transmitted viruses.

After establishment of clonal colonies, a series of brief tests were conducted with excised shoot tips, from a range of cultivars and selections, held in vials of water using a procedure similar to Brodel and Schaefers (1980) to determine which cultivars the aphids would or would not colonize. Assays of excised shoot tips were performed in the greenhouse under heavy aphid pressure. Results were not verified through replication but were used to direct searches for potentially divergent aphid biotypes in the field on those cultivars that remained uncolonized after 4 to $5 \mathrm{~d}$. To determine which biotype they represented, additional isolates were obtained from aphids found in the field on cultivars and selections that had been previously regarded as aphid-resistant but which were colonized in excised shoot-tip assays. All characterization of aphid isolates was performed by a separate, replicated no-choice colonization assay (see subsequently).

ResistanCE SCREening. Each of the 12 aphid isolates was screened for the ability or inability to colonize 15 raspberry cultivars (Algonquin, Cascade Bounty, Chemainus, Cowichan, Latham, Malahat, Meeker, Nanoose, Newburgh, Qualicum, Rudi, Saanich, Tulameen, Ukee, Willamette) and four selections (BC 90-19-34, BC 93-16-43, BC 10-4-101, BC 10-8-102) in a no-choice test (Table 1). Cultivars and selections were chosen for screening based on the results of excised shoot-tip assays and/or previous studies identifying them, or one of their progenitors, as sources of resistance (Daubeny and Sjulin, 1984; Daubeny and Stary, 1982). In addition, 'Skeena' and 'Creston' were screened for resistance to biotype E only to establish whether it was possible that they were the source of resistance observed in 'Nanoose', 'Rudi', and 'Ukee'.

In each test, five adult aphids from the stock colony were placed on the growing tip of a single potted plant in a screened cage and allowed to settle. Plants were checked for evidence of colonization (three or more adults and nymphs) or lack of colonization (two or fewer adults and no nymphs) at $4 \mathrm{~d}$ and 1 week. After 1 week the plant was classified as resistant or susceptible. In cases in which no adults or nymphs were observed after $4 \mathrm{~d}$, the plant was considered to be resistant and screening was ended. The order by which cultivars were tested against specific isolates was randomized. Each cultivar $\times$ isolate combination was tested five times using a new plant for each test. Whenever possible, the same set of plants was used to test each isolate to minimize potential variation caused by the plants themselves. To maintain freshly growing shoot tips suitable for aphid colonization, and so that plants could be re-used throughout the course of the experiment, plants were regularly trimmed to stimulate new growth. All aphids were removed from plants between tests by placing them in a box for $24 \mathrm{~h}$ with two dichlorvos strips (Hot Shot No-Pest Strip; United Industries Corp., St. Louis, MO) and then waiting a minimum 
Table 1. Susceptibility (S) and resistance (R) of 15 red raspberry cultivars and four selections to six biotypes of the aphid Amphorophora agathonica in southwestern British Columbia. ${ }^{\mathrm{z}}$

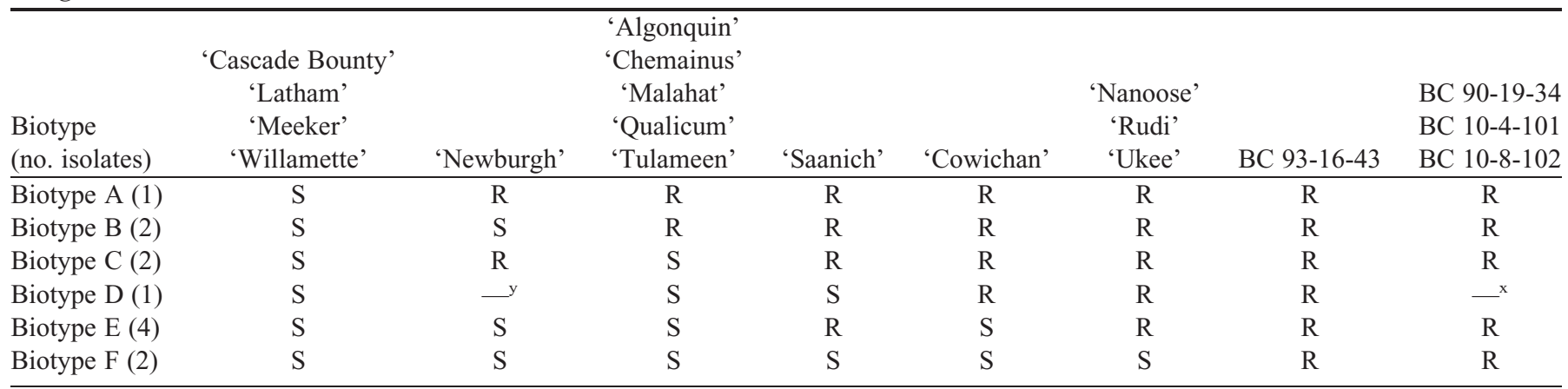

${ }^{\mathrm{z}}$ The number of isolates of each biotype found is indicated in parentheses after the biotype designation.

'Unable to test, but expected to be resistant based on responses to 'Qualicum' and 'Cowichan'.

${ }^{\mathrm{x}}$ Unable to test.

of $72 \mathrm{~h}$ before using the plant in a subsequent test. Unfortunately, as a result of the loss of the biotype D isolate partway through this study, it was not possible to test this biotype against 'Newburgh' or three of the four selections.

In a separate experiment, seedlings from the cross BC 93-16$43 \times$ 'Malahat' were screened for resistance to three aphid biotypes (designated types B, E, and F) to confirm resistance and observe segregation of resistance (Table 2). Screening for resistance was performed using potted plants and the procedures described by Dossett and Finn (2010). This experiment took place under artificial lighting (16-h daylength) in an insectary and was performed twice for each seedling against biotypes D and $\mathrm{E}$ and once for biotype F. Briefly, plants were placed on the bench in the insectary in a randomized fashion, inoculated with three apterous adult aphids, and checked for evidence of colonization after 1 week. Plants with more than 10 aphids were considered susceptible, plants with three to 10 aphids were placed back on the bench for further evaluation, and plants with fewer than three aphids had aphids added to them. Plants were rechecked four more times at 4-d intervals. Segregation ratios were tested for goodness of fit to models of inheritance using chi-square tests performed in SAS (Version 9.1; SAS Institute, Cary, NC).

\section{Results}

In all aphid screening tests, there was complete agreement between replications with regard to whether a cultivar or selection was considered resistant or susceptible to colonization by the aphid isolate being tested. There was no case in which more than one adult aphid (and no nymphs) was present on resistant plants after 1 week, and in all cases, susceptible plants had at least four adults and many nymphs of varying sizes after 1 week. From these data, we can conclude that the screening procedure was adequate to reliably and repeatedly determine the resistance status of each cultivar against the aphid isolates in question.

Results of screening the 12 aphid isolates indicated that they could be separated into six biotypes based on their ability or inability to colonize a differential set of raspberry cultivars, and each of the 15 cultivars tested, including those originally selected for aphid resistance, was found to support aphid colonies of at least one biotype (Table 1). A variety of conventions are used across crop species for designating aphid biotypes. We have chosen to use letters in the designation of $A$. agathonica biotypes to avoid potential confusion with the numbering system currently in place for designation of aphid resistance genes in raspberry.

'Cascade Bounty', 'Meeker', 'Latham', and 'Willamette' were readily colonized by all six biotypes we identified. 'Algonquin', first released as germplasm homozygous for $A g_{1}$ (Daubeny and Sjulin, 1984), was among the group found to be readily colonized by biotypes $\mathrm{C}, \mathrm{D}, \mathrm{E}$, and $\mathrm{F}$ (Table 1). Based on this result, and the observations of 'Saanich' and 'Cowichan' being resistant to colonization by biotype $\mathrm{C}$ aphids, we believe that biotype $\mathrm{C}$ represents aphids capable of overcoming $A g_{1}$, as was first described by Daubeny and Anderson (1991), and that biotypes D, E, and $\mathrm{F}$ represent aphids capable of overcoming $A g_{I}$ in addition to one or more other sources of resistance.

Three recent releases, 'Nanoose', 'Rudi', and 'Ukee', had resistance to A. agathonica biotypes $\mathrm{A}, \mathrm{B}, \mathrm{C}, \mathrm{D}$, and $\mathrm{E}$ but were readily colonized by biotype $\mathrm{F}$ (Table 1 ). These three

Table 2. Results of the chi-square test for goodness of fit to expected segregation ratios for aphid resistance in seedlings of BC $93-16-43 \times$ 'Malahat' red raspberries. ${ }^{z}$

\begin{tabular}{|c|c|c|c|c|c|c|c|c|c|c|}
\hline \multirow[b]{2}{*}{ Cross } & \multicolumn{5}{|c|}{ Biotype B } & \multicolumn{5}{|c|}{ Biotypes E, F } \\
\hline & Resistant & Susceptible & $\begin{array}{l}\text { Expected } \\
\text { ratio }\end{array}$ & $\chi^{2}$ & $P$ & Resistant & Susceptible & $\begin{array}{l}\text { Expected } \\
\text { ratio }\end{array}$ & $\chi^{2}$ & $P$ \\
\hline BC 93-16-43 × 'Malahat' & 143 & 53 & $3: 1$ & 0.44 & 0.51 & 84 & $76^{y}$ & $1: 1$ & 0.40 & 0.53 \\
\hline
\end{tabular}

${ }^{\mathrm{z}}$ Results to screening against three aphid biotypes give good fit to a model where 'Malahat' is heterozygous for the resistance allele $A g_{l}$ and $\mathrm{BC}$ 93-16-43 is heterozygous for an unknown single dominant resistance allele other than $A g_{1}$. Italicized entries are the results of chi-square tests showing the lack of fit under the $A g_{2} / \mathrm{Ag}_{3}$ model proposed by Daubeny and Stary (1982).

${ }^{\mathrm{y}}$ Total number of seedlings does not match biotype B results because of the death of some seedlings between screening experiments. 
cultivars are progeny of crosses between clones carrying $A g_{1}$ and BC 86-41-15, a second-backcross derivative of a wild $R$. strigosus clone known as Dalhousie Lake 4 (Fig. 1A). Knowing that 'Meeker' and 'Willamette', also in the pedigree of BC 86-41-15, were susceptible to all of the biotypes we identified, we screened 'Skeena' and 'Creston', two other cultivars from which BC $86-41-15$ is derived, against biotype E. As expected for resistance from $A g_{1}$, we found both to be susceptible (Fig. 1A). Dalhousie Lake 4, Kanata-B, and Kinburne were $R$. strigosus clones grown from seed originating in the vicinity of Ottawa, Ontario, Canada, and which carried aphid resistance believed to be conferred by the combination of dominant alleles at complementary loci $\mathrm{Ag}_{2}$ and $\mathrm{Ag}_{3}$ (Daubeny and Stary, 1982). Initially, we believed that this was the likely source of resistance found in 'Nanoose', 'Rudi', and 'Ukee', but Dalhousie Lake 4 and the other original $R$. strigosus clones are no longer available for confirmation. Because of this, we tested BC 93-16-43 (Kanata-B $\times$ 'Tulameen'), a more recent selection thought to represent the same source of resistance, against all biotypes. We found that none of the $A$. agathonica biotypes, including biotype F, were capable of colonizing BC 93-16-43. Furthermore, our records, from 1987, of segregation for resistance in the cross that produced $\mathrm{BC} 86-41-15$ show chi-square ratios equally supportive of resistance in BC 82-17-10 coming from either one resistance allele or two complementary alleles in addition to $\mathrm{Ag}_{1}$ ( $P=0.46$ and $P=0.59$, respectively). These results cast doubt on the theory that resistance in Kanata-B and Dalhousie Lake 4 are conferred by the same resistance alleles as originally proposed by Daubeny and Stary (1982) and create some uncertainty regarding the model of $\mathrm{Ag}_{2} / \mathrm{Ag}_{3}$ from Dalhousie Lake 4 giving resistance in 'Rudi', 'Ukee', and 'Nanoose'. Although Dalhousie Lake 4 appears to be the most likely source for this resistance, the definitive statements regarding the source
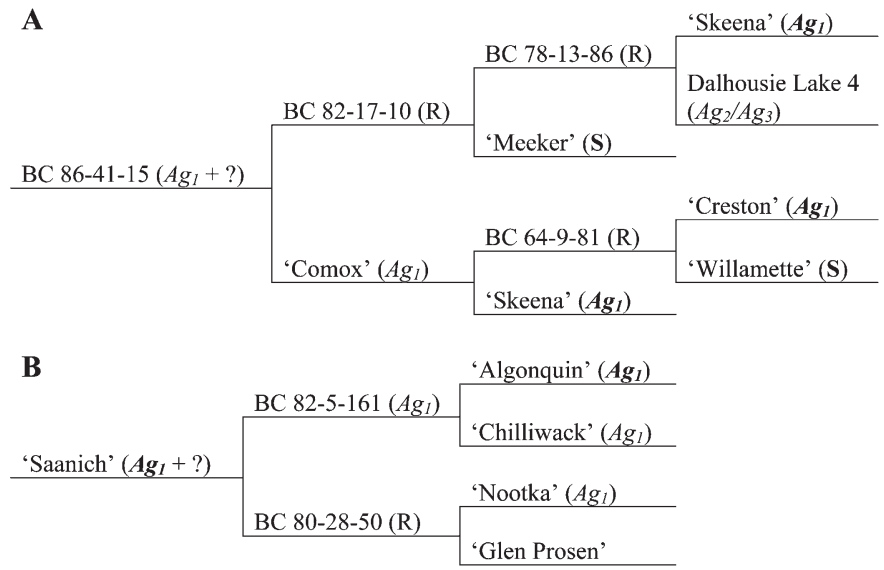

Fig. 1. Pedigrees of (A) BC 86-41-15 and (B) 'Saanich' red raspberries. Results of biotype screens indicate that both carry $A g_{1}$ in addition to another distinct source of resistance. Resistance alleles or susceptibility (S) are indicated in parentheses after selection or cultivar names. All numbered selections were originally selected for resistance to aphids of unknown biotype and have been designated by. Resistance confirmed by screening in this study is indicated in bold, whereas alleles that are suspected but unconfirmed by this study appear in normal font. BC 86-41-15 appears to be a source of resistance to biotype E aphids, likely conferred by Dalhousie Lake 4 because of susceptibility in 'Creston', 'Meeker', 'Skeena', and 'Willamette'. 'Saanich' has resistance to biotypes $\mathrm{C}$ and $\mathrm{E}$ despite susceptibility in 'Algonquin'. 'Chilliwack' and 'Nootka' were not tested but are also probably susceptible, leaving 'Glen Prosen' as the most likely source of resistance, although all three need further testing. and inheritance of resistance to biotype E observed in progenies of BC 86-41-15 cannot be made at this time.

After determining that aphid resistance in BC 93-16-43 has not yet been overcome by the six aphid biotypes we identified, we screened seedlings of the cross BC 93-16-43 × 'Malahat' against biotypes $\mathrm{B}, \mathrm{E}$, and $\mathrm{F}$ in the insectary to confirm inheritance of this resistance source. These results showed that resistance against biotypes $\mathrm{E}$ and $\mathrm{F}$ were $100 \%$ concurrent and that all seedlings susceptible to biotype B (27\% of total) were also susceptible to biotypes E and F (47.5\% of total). Chisquare tests for goodness of fit are supportive of the hypothesis that BC 93-16-43 and 'Malahat' are heterozygous for single dominant resistance alleles at separate loci with BC 93-16-43 carrying a single dominant allele conferring resistance to all six biotypes identified thus far [expected ratio 3:1 (biotype B) $P=0.51$, expected ratio $1: 1$ (biotypes E, F) $P=0.53$ ] and do not fit the $\mathrm{Ag}_{2} / \mathrm{Ag}_{3}$ model (Table 2).

In addition to BC 93-16-43, three additional selections were tested and identified as sources of resistance that appear to have not yet been broken. These three selections could not be tested against biotype D (Table 1). All three are crosses between $R$. strigosus and cultivars with resistance that has been broken. BC 90-19-34 ('Tulameen' $\times$ BC 86-62-3) is a selection whose $R$. strigosus parent (BC 86-62-3) came from wild seed collected near Lake George, $\mathrm{MN}$, and was initially selected for resistance to root rot. After screening progeny of BC 90-19-34 to biotype $\mathrm{B}$ aphids for another project and noting an excess of resistant seedlings, we screened BC 90-19-34 against biotypes A, B, $\mathrm{C}$, E, and $\mathrm{F}$ and confirmed its resistance (Table 1). We also screened seedlings from the cross 'Malahat' $\times$ BC 90-19-34 to biotype $\mathrm{E}$ and found segregation for resistance. Unfortunately, as a result of the small number of seedlings from this cross (17) and observed segregation distortion of other major loci (data not shown), we cannot make any firm conclusions about the inheritance of resistance from this source without further study. However, these results indicate that BC 90-19-34 carries $A g_{1}$ resistance from its parent 'Tulameen' as well as an additional dominant source of resistance from its $R$. strigosus parent.

BC 10-4-101 ('Cascade Delight' $\times$ Heffley Creek) and BC 10-8-102 ('Cowichan' $\times$ Heffley Creek) were first identified as resistant to biotype $\mathrm{E}$ during routine screening of all of the PARC breeding programs' seedlings in the greenhouse. These two selections were chosen for further testing because we noted that greater than $90 \%$ of the seedlings from crosses involving the wild $R$. strigosus selection from Heffley Creek, British Columbia, Canada, were resistant. Both of these selections were confirmed to be resistant to all five biotypes we were able to screen them against (Table 1). Aphids have not been found colonizing BC 90-19-34 or BC 93-16-43 in the field, so new biotypes capable of colonizing these selections have not been identified to date; $\mathrm{BC}$ 10-4-101 and $\mathrm{BC} 10-8-102$ have been kept in the greenhouse and screenhouse in Agassiz, British Columbia, Canada, and have not yet been exposed to aphids in the field.

\section{Discussion}

Until this study, it was believed that two biotypes (regular and $A g_{1}$-breaking) of $A$. agathonica were present in the commercial red raspberry production region of northwest Washington and southwest British Columbia (Converse et al., 1971; Daubeny and Anderson, 1991, 1993). Our data clearly 
suggest that there is a minimum of six biotypes of $A$. agathonica found in this area (Table 1). Because the methods by which we sampled aphids were directed and non-random, no definitive statements can be made regarding the presence of additional biotypes or the relative abundance of the biotypes we identified. Furthermore, although all of the cultivars released from the AAFC-PARC breeding program in recent years have been selected for aphid resistance, the resistance found in each has been overcome by one or more biotypes. This is not entirely unlike the situation in the United Kingdom, where five biotypes of the european large raspberry aphid (Amphorophora idaei Börn.) are currently recognized (McMenemy et al., 2009).

Only a single aphid biotype was recognized in North America until the discovery of aphids capable of colonizing plants with $A g_{1}$ were discovered in the early 1990s (Daubeny and Anderson, 1991, 1993). This was mostly based on a study by Converse et al. (1971), which examined colonization by wild aphids in two geographically disparate regions (Agassiz, British Columbia, Canada, and Burlington, VT) on an identical set of cultivars. Although the authors of that study only found evidence for aphids capable of feeding on raspberry cultivars not carrying $A g_{1}$, the methods used were not sensitive enough to conclude that only a single biotype was present in part, because they ignored the natural variability of wild aphid populations and did not screen cultivars with clonal aphid isolates. Under this scenario, all aphids colonizing any plant would be assumed to be of the same biotype, regardless of the genetic background of the plant, and plants with resistance genes that had already been overcome would appear to give the same reaction as those with no known resistance. Only plants with one or more resistance genes that had not yet been overcome, or multiple resistance genes that still worked in combination to give resistance to local aphid populations, would appear resistant.

A possible example of this scenario is 'Newburgh' ('Newman' $x$ 'Herbert'), which is unarguably the most successful progeny of 'Herbert', the first cultivar recognized as resistant to $A$. agathonica (Winter, 1929). Although historical reports vary between considering 'Newburgh' resistant or susceptible (Table 3), we found it to be resistant to biotype A and C aphids and susceptible to biotypes B, E, and F. Darrow (1937) considered 'Herbert' and 'Newburgh' to be resistant, but Huber and Schwartze (1938) had mixed results with 'Herbert' and 'Newburgh', considering both to be "partially resistant."

Table 3. Summary of previous studies classifying resistance or susceptibility of 'Newburgh' red raspberry to the aphid Amphorophora agathonica.

\begin{tabular}{|c|c|c|c|}
\hline Location of test & Result & $\mathrm{Yr}$ & Source \\
\hline Unknown & Resistant & Unknown & Darrow, 1937 \\
\hline Puyallup, WA & Partially resistant ${ }^{\mathrm{z}}$ & $1935-1937$ & Huber and Schwartze, 1938 \\
\hline Vancouver, BC & Susceptible & $1954-1957$ & Stace-Smith, 1960 \\
\hline Amherst, MA & Resistant & 1960 & Converse and Bailey, 1961 \\
\hline $\begin{array}{l}\text { Agassiz, British Columbia, } \\
\text { Canada }\end{array}$ & Susceptible & $1964-1965$ & Daubeny, 1966 \\
\hline Fredonia, NY & Resistant & 1965 & Schaefers, 1968 \\
\hline $\begin{array}{l}\text { Agassiz, British Columbia, } \\
\text { Canada }\end{array}$ & Susceptible & $1966-1967$ & Converse et al., 1971 \\
\hline Burlington, VT & Susceptible ${ }^{y}$ & 1966-1967 & Converse et al., 1971 \\
\hline Geneva, NY & Susceptible & $1970-1971$ & Kennedy et al., 1973 \\
\hline
\end{tabular}

$\overline{{ }^{\mathrm{z}} \text { Based on conflicting results between greenhouse and field counts and across greenhouse replicates. }}$ ${ }^{y}$ Classified as susceptible but not statistically different from 'Rideau', which has resistance conferred by $A g_{l}$.
In their tests, they found that 'Newburgh' and 'Herbert' were colonized by small numbers of aphids in the field, and results from their greenhouse tests differed across replicates. Because Huber and Schwartze (1938) were not working with a single clonal isolate, it seems likely that their results may be explained if resistance in 'Newburgh' is derived from 'Herbert', and aphids capable of overcoming this source were present in the field and in some, but not all, of their greenhouse replications.

'Newburgh' was still considered to be resistant in field plantings at Amherst, MA, and Fredonia, NY, as late as the early and mid-1960s (Converse and Bailey, 1961; Schaefers, 1968). However, by 1970 and 1971, Kennedy et al. (1973) noted that aphids readily colonized 'Newburgh' at Geneva, NY, with numbers of $A$. agathonica on 'Newburgh' exceeding those on the susceptible 'Willamette' in both years. Given these observations, it seems likely that 'Newburgh' was resistant to A. agathonica when it was first introduced and that resistance subsequently broke down in Washington and British Columbia and then later in New England and upstate New York. The theory of a gene conferring resistance to $A$. agathonica in 'Newburgh' is also supported by our observations of biotype $\mathrm{E}$ aphids. 'Cowichan' ('Newburgh' $\times$ 'Qualicum'), which can be used to distinguish between biotypes $\mathrm{C}$ and $\mathrm{E}$, appears to have inherited resistance from both of its parents because neither biotype $\mathrm{B}$ nor biotype $\mathrm{C}$ aphids are capable of colonizing it, but they are capable of colonizing 'Newburgh' and 'Qualicum', respectively (Table 1).

Our data from the cross of BC 93-16-43 × 'Malahat' fit a segregation ratio expected for inheritance of $A g_{1}$ from Malahat but do not fit the model of $\mathrm{Ag}_{2} / \mathrm{Ag}_{3}$ from BC 93-16-43 as proposed by Daubeny and Stary (1982) for its parent, Kanata-B (Table 2). Because this model was based on field observations and not from clonal aphid isolates in the greenhouse, their observations may also have been the result of mixed aphid populations used in the greenhouse screening and the presence of at least two aphid biotypes in the field. Under this scenario, plants with either $\mathrm{Ag}_{2}$ or $\mathrm{Ag}_{3}$ would still be colonized by one aphid biotype and only plants with both would remain uncolonized. Daubeny and Stary (1982) do indicate that small numbers of aphids capable of colonizing plants carrying $\mathrm{Ag}_{2}$ and $\mathrm{Ag}_{3}$ were occasionally found. This could be from mating of aphids of the two biotypes producing offspring capable of overcoming both genes or it could be from uncertainty in the genetic composition of the resistance in any given plant. Our results showing resistance in BC 93-16-43 (from Kanata-B) and BC 86-41-15 (presumably originating from Dalhousie Lake 4) to be different and segregation ratios suggesting that resistance in $\mathrm{BC} 93-16-43$ is at a single locus could be interpreted to fit this scenario, but this is only from one cross. Either more crosses will be needed to confirm this result or the resistance will need to be mapped with genetic markers to determine if other loci are involved. In either case, further study is needed to reconcile our results with those of Daubeny and Stary (1982). 
Resistance to biotype C aphids in 'Saanich' was unexpected, in part because 'Saanich' was not considered to have a source of resistance other than $A g_{1}$ in its ancestry. The parents of 'Saanich' have been discarded from the breeding program and are not available for further study, but one possibility is that 'Saanich' may have inherited resistance from its grandparent, 'Glen Prosen' (Fig. 1B). In addition to having 'Lloyd George' as an ancestor, 'Glen Prosen' is a derivative of SHRI AR1 ('Burnetholm' $\times$ self), a selection determined by Daubeny (1972) to represent a source of resistance to $A$. agathonica different from $A g_{1}$. This possibility should be explored and seedlings from 'Saanich' crosses should be screened against different aphid biotypes to help clarify the source and inheritance of this resistance. Alternatively, it is possible that 'Saanich' has strong horizontal resistance to A. agathonica. It was noted that although biotype $\mathrm{F}$ aphids were capable of colonizing 'Saanich' by the definition outlined in the methods, they appeared to do so much more slowly than biotype D (data not shown). This was not noted for biotype $\mathrm{F}$ aphids colonizing other cultivars, making it unlikely that the difference is merely the result of a lower fecundity of the biotype itself but is a function of the cultivar they were colonizing or the specific biotype $\times$ cultivar combination. This could be from strong horizontal resistance and differential ability of aphid biotypes to overcome these mechanisms. Unfortunately, because the isolate of biotype D aphids was lost toward the end of this project, we were unable to pursue direct comparisons of the reproductive rates of different biotypes on 'Saanich' and other cultivars to examine this difference further. Similarly, resistance found in 'Nanoose', 'Rudi', and 'Ukee' appears to come from their common parent, BC 86-41-15, but the ultimate source of this resistance cannot be determined at this time because all known progenitors except for Dalhousie Lake 4 are susceptible (Fig. 1A). In any case, both of these sources of resistance have been compromised by at least one aphid biotype and will not be of much benefit to the development of new resistant cultivars.

The list of six biotypes we have identified is not intended to be an exhaustive identification of all biotypes currently present in the region but, rather, a starting point to facilitate the identification of biotypes found in the field in future studies. In addition to the six biotypes we have identified, the data suggest the likelihood of a seventh. We note that biotype D is capable of colonizing 'Saanich', but not 'Cowichan', and that biotype E is capable of colonizing 'Cowichan' but not 'Saanich'. In addition, biotype $\mathrm{F}$ is capable of colonizing both, but also readily colonizes 'Nanoose', 'Rudi', and 'Ukee'. With some exceptions, the majority of aphid resistance genes in red raspberry and other crops had been determined to be inherited as dominant traits controlled by a single locus (Smith and Clement, 2012). If a gene-for-gene model for resistance is followed, then we would expect the presence an additional biotype capable of colonizing 'Saanich' and 'Cowichan' but not 'Nanoose', 'Rudi', or 'Ukee'. Under a gene-for-gene model, such a biotype could arise from the mating of biotype D and $\mathrm{E}$ aphids or with either $\mathrm{D}$ or E mating to biotype $\mathrm{F}$, similar to the occurrence of $A$. idaei strains 1 to 4 in the United Kingdom (Briggs, 1965). More extensive field surveys are needed to determine the occurrence of this biotype and the relative prevalence of the biotypes we have identified.

Although we have confirmed three sources of resistance to the identified aphid biotypes, these sources all originate from the wild North American red raspberry, R. strigosus. One question that remains to be answered is how durable and widely effective these sources may be. Because they have originated from wild plants in North America, they have had prolonged exposure to native aphid populations and local populations of A. agathonica may have already overcome them. As such, it is possible that newly identified resistance genes from $R$. strigosus may be regionally limited in their effectiveness, and screening of the three resistance sources we have identified should take place in other parts of North America for confirmation of resistance to local aphid populations. The corollaries to this are that new sources of resistance may be more likely to be found in distant wild raspberry populations than in local ones and that resistance genes to all known biotypes (i.e., "universal" resistance genes) may be more likely to originate from sources outside of the range of $A$. agathonica but within that of closely related aphid species. Before breeders began systematically searching for North American sources of resistance to A. agathonica, several authors (Daubeny, 1972; Knight et al., 1958; Stace-Smith, 1960) noted that resistance to A. agathonica seemed to come from primarily European sources, and sources of resistance to its European counterpart, A. idaei, are more prevalent in North American raspberries. 'Lloyd George', from which $A g_{1}$ originates, was found growing as a wild or escaped seedling in Kent, UK. Likewise, other sources of resistance identified by Daubeny (1972) come from Europe. 'Burnetholm' was found as a chance seedling in Lanarkshire, Scotland, and 'Pyne's Royal' is also derived from $R$. idaeus in the United Kingdom. Neither of these cultivars was available for testing in this study, but both should be examined more closely as potential resistance sources, and screening wild germplasm from outside of North America for resistance may also be particularly useful.

Historically, 'Lloyd George' was the most commonly used source of aphid resistance for raspberry breeding in North America. This resistance was considered to be effective at stopping the spread of viruses and was durable for more than 50 years, until large numbers of plants carrying $A g_{1}$ were being grown in northwestern Washington and southwestern British Columbia. This resistance has since broken down and all of the cultivars we tested have been found to be susceptible to at least one aphid biotype. As such, new sources of resistance to $A$. agathonica are needed to sustain efforts to breed cultivars escaping from infection by important aphid-transmitted viruses such as raspberry leaf mottle virus, raspberry latent virus, rubus yellow net virus, and black raspberry necrosis virus.

It is now clear that part of the overwhelming success of resistance conferred by $A g_{1}$ is because of difficulties in the ability of aphids to sustain phloem feeding, thereby reducing the efficiency with which they are able to acquire phloemlimited viruses (Lightle et al., 2012). Understanding the biology of resistance mechanisms will be important for gauging how durable new sources of resistance may be and how effective they will be at the goal of slowing virus transmission. To date, only two aphid resistance genes in any crop have been cloned and sequenced (Smith and Clement, 2012), leaving a gaping hole in our understanding of the biology of these systems. This work may be aided by mapping studies designed to identify markers for aphid resistance for use in marker-assisted selection (Sargent et al., 2007) by narrowing the search for candidate genes for aphid resistance. By the same token, mapping studies will be necessary to identify markers and linkages for aphid resistance genes so that new sources can be efficiently combined 
to maintain their durability and prevent future breakdown of resistance.

\section{Conclusions}

To date, we have identified six biotypes of $A$. agathonica in southwestern British Columbia. Every cultivar that we tested, including most of those released by public breeding programs in Pacific northwestern North America over the last few decades, can be colonized by at least one of these biotypes. The differential set of cultivars identified in this project will aid in efforts to determine the prevalence of existing biotypes in the field as well as serve as a benchmark for the identification of new biotypes and resistance sources in the future.

We have also identified three sources of resistance to A. agathonica, originating from wild North American red raspberry germplasm, that have not been overcome by these biotypes. These, and other new sources of resistance, should be characterized and mapped with genetic markers so that pyramiding of resistance genes is feasible. Until strong sources of horizontal resistance are identified, durable resistance will only come from combining multiple resistance sources.

\section{Literature Cited}

Briggs, J.B. 1965. The distribution, abundance, and genetic relationships of four strains of the Rubus aphid [Amphorophora rubi (Kalt.)] in relation to raspberry breeding. J. Hort. Sci. 40:109-117.

Brodel, C.F. and G.A. Schaefers. 1980. Use of excised leaflets of red raspberry to screen for potential nonpreference resistance to Amphorophora agathonica. HortScience 15:513-514.

Converse, R.H. and J.S. Bailey. 1961. Resistance of some Rubus varieties to colonization by Amphorophora rubi in Massachussetts. Proc. Amer. Soc. Hort. Sci. 78:251-255.

Converse, R.H., H.A. Daubeny, R. Stace-Smith, L.M. Russell, E.J. Koch, and S.C. Wiggans. 1971. Search for biological races in Amphorophora agathonica Hottes on red raspberries. Can. J. Plant Sci. 51:81-85.

Darrow, G.M. 1937. Blackberry and raspberry improvement, p. 496553. In: Yearbook of the United States Department of Agriculture. U.S. Government Printing Office, Washington, DC.

Daubeny, H.A. 1966. Inheritance of immunity in the red raspberry to the North American strain of the aphid Amphorophora rubi Kltb. Proc. Amer. Soc. Hort. Sci. 88:346-351.

Daubeny, H.A. 1972. Screening red raspberry cultivars and selections for immunity to Amphorophora agathonica Hottes. HortScience 7: 265-266.

Daubeny, H.A. and A. Anderson. 1991. 'Tulameen' red raspberry. HortScience 26:1336-1338.

Daubeny, H.A. and A.K. Anderson. 1993. Achievements and prospectsThe British Columbia red raspberry breeding program. Acta Hort. 352:285-293.

Daubeny, H.A. and T.M. Sjulin. 1984. BC 72-1-7 red raspberry. HortScience 19:733-734.
Daubeny, H.A. and R. Stace-Smith. 1963. Note on immunity to the North American strain of the red raspberry mosaic vector, the aphid, Amphorophora rubi Kalb. Can. J. Plant Sci. 43:413-415.

Daubeny, H.A. and D. Stary. 1982. Identification of resistance to Amphorophora agathonica in the native North American red raspberry. J. Amer. Soc. Hort. Sci. 107:593-597.

Dossett, M.D. and C.E. Finn. 2010. Identification of resistance to the large raspberry aphid in black raspberry. J. Amer. Soc. Hort. Sci. 135:438-444.

Halgren, A., I.E. Tzanetakis, and R.R. Martin. 2007. Identification, characterization, and detection of black raspberry necrosis virus. Phytopathology 97:44-50.

Huber, G.A. and C.D. Schwartze. 1938. Resistance in the red raspberry to the mosaic vector Amphorophora rubi Kalt. J. Agr. Res. 57:623633.

Kempler, C., H. Hall, and C.E. Finn. 2012. Raspberry, p. 263-304. In: Badenes, M.L. and D.H. Byrne (eds.). Fruit breeding. Springer, New York, NY.

Kennedy, G.C., G.A. Schaefers, and D.K. Ourecky. 1973. Resistance in red raspberry to Amphorophora agathonica Hottes and Aphid rubicola Oestlund. HortScience 8:311-313.

Knight, R.L., E. Keep, and J.B. Briggs. 1958. Genetics of resistance to Amphorphora rubi (Kalt.) in the raspberry I. The gene $A_{1}$ from Baumforth A. J. Genet. 56:261-280.

Lightle, D.M., M. Dossett, E.A. Backus, and J.C. Lee. 2012. Location of the mechanism of resistance to Amphorophora agathonica (Hemiptera: Aphididae) in red raspberry. J. Econ. Entomol. 105:1465-1470.

McMenemy, L.S., C. Mitchell, and S.N. Johnson. 2009. Biology of the european large raspberry aphid (Amphorophora idaei): Its role in virus transmission and resistance breakdown in red raspberry. Agr. For. Entomol. 11:61-71.

Quito-Avila, D.F., D. Lightle, J. Lee, and R.R. Martin. 2012. Transmission biology of Raspberry latent virus, the first aphid-borne Reovirus. Phytopathology 102:547-553.

Rankin, W.H. 1927. Mosaic in raspberries. New York State Agr. Expt. Sta. Bul. 543.

Rankin, W.H. and J.P. Hockey. 1922. Mosaic and leaf curl (yellows) of the cultivated red raspberry. Phytopathology 12:253-264.

Sargent, D.J., F. Fernández-Fernández, A. Rys, V.H. Knight, D.W. Simpson, and K.R. Tobutt. 2007. Mapping of $A 1$ conferring resistance to the aphid Amphorophora idaei and $d w$ (dwarfing habit) in red raspberry (Rubus idaeus L.) using AFLP and microsatellite markers. BMC Plant Biol. 7:15.

Schaefers, G.A. 1968. Control of the aphid Amphorophora agathonica in raspberry nursery stock. J. Econ. Entomol. 61:384-387.

Smith, C.M. and S.L. Clement. 2012. Molecular bases of plant resistance to arthropods. Annu. Rev. Entomol. 57:309-328.

Stace-Smith, R. 1960. Studies on Rubus virus diseases in British Columbia. VI. Varietal susceptibility to aphid infestation in relation to virus acquisition. Can. J. Bot. 38:283-285.

Tzanetakis, I.E., A. Halgren, N. Mosier, and R.R. Martin. 2007. Identification and characterization of raspberry mottle virus, a novel member of the Closteroviridae. Virus Res. 127:26-33.

Winter, J.D. 1929. A preliminary account of the raspberry aphids. Minnesota Agr. Expt. Sta. Tech. Bul. 61. 